\title{
Major Histocompatibility Complex Class III Genes and Susceptibility to Immunoglobulin A Deficiency and Common Variable Immunodeficiency
}

\author{
John E. Volanakis," Zeng-Bian Zhu," Frederick M. Schaffer," Kevin J. Macon," John Palermos," Bruce O. Barger," \\ Rodney Go," R. Duncan Campbell,' Harry W. Schroeder, Jr.," and Max D. Cooper ${ }^{\star \star \star}$ \\ ${ }^{*}$ Division of Clinical Immunology and Rheumatology, Department of Medicine, ${ }^{\ddagger}$ Division of Developmental and Clinical Immunology, \\ Departments of Pediatrics, Medicine, Microbiology, and Pathology, and the Comprehensive Cancer Center, ${ }^{\S}$ Department of Surgery, \\ "Department of Epidemiology, University of Alabama at Birmingham, ${ }^{* *}$ Howard Hughes Medical Institute, Birmingham, \\ Alabama 35294; and "Medical Research Council Immunochemistry Unit, University of Oxford, Oxford OX1 3QU, United Kingdom
}

\begin{abstract}
We have proposed that significant subsets of individuals with IgA deficiency (IgA-D) and common variable immunodeficiency (CVID) may represent polar ends of a clinical spectrum reflecting a single underlying genetic defect. This proposal was supported by our finding that individuals with these immunodeficiencies have in common a high incidence of $\mathrm{C4A}$ gene deletions and $\mathrm{C} 2$ rare gene alleles. Here we present our analysis of the MHC haplotypes of 12 IgA-D and 19 CVID individuals from 21 families and of 79 of their immediate relatives. MHC haplotypes were defined by analyzing polymorphic markers for 11 genes or their products between the HLA-DQB1 and the HLA-A genes. Five of the families investigated contained more than one immunodeficient individual and all of these included both IgA-D and CVID members. Analysis of the data indicated that a small number of MHC haplotypes were shared by the majority of immunodeficient individuals. At least one of two of these haplotypes was present in 24 of the 31 (77\%) immunodeficient individuals. No differences in the distribution of these haplotypes were observed between IgA-D and CVID individuals. Detailed analysis of these haplotypes suggests that a susceptibility gene or genes for both immunodeficiencies are located within the class III region of the MHC, possibly between the C4B and C2 genes. (J. Clin. Invest. 1992. 89:1914-1922.) Key words: common variable $\bullet$ complement $\bullet$ immunodeficiency - immunoglubulin A deficiency • major histocompatibility complex
\end{abstract}

\section{Introduction}

With a prevalence of $\sim 1$ in 800 Caucasians (1), selective IgA deficiency $(\operatorname{IgA}-\mathrm{D})^{1}$ is the most frequently recognized primary

This study was presented in part at the Meeting of the European Group for Immunodeficiencies, Oxford, England, 26-29 September 1990, and at the International Workshop on Primary Immunodeficiency Diseases, Hokkaido, Japan, 1-3 September 1991.

Address correspondence to Dr. John E. Volanakis, Division of Clinical Immunology and Rheumatology, UAB Station, THT 437, Birmingham, AL 35294.

Received for publication 17 September 1991 and in revised form 21 February 1992.

1. Abbreviations used in this paper: CVID, common variable immunodeficiency; IDDM, insulin-dependent diabetes mellitus; IgA-D, IgA deficiency; PCR, polymerase chain reaction; RFLP, restriction fragment length polymorphism; TNF $\alpha$, tumor necrosis factor alpha.

J. Clin. Invest.

(C) The American Society for Clinical Investigation, Inc. 0021-9738/92/06/1914/09 \$2.00

Volume 89, June 1992, 1914-1922 immunodeficiency. The clinical consequences of IgA-D are highly variable. Many of the affected individuals have no obvious health problems, while others may have recurrent infections, gastrointestinal disorders, autoimmune diseases, allergies, or malignancies (reviewed in reference 2). A central feature in the pathogenesis of IgA-D is an arrest in B cell differentiation. Affected individuals have normal numbers of IgA-bearing B cell precursors but a profound deficit in IgA-producing plasma cells (3). The IgA ${ }^{+}$B cells in IgA-D individuals resemble their relatively immature counterparts in the newborn in that most of them bear IgA and IgM, whereas relatively few $(<10 \%)$ express IgA alone, as would be expected for normal individuals beyond infancy (4). These observations imply integrity of the $\mathrm{C} \alpha$ genes and the basic genetic elements required for isotype switching, and suggest an immunoregulatory defect.

Common variable immunodeficiency (CVID), defined by panhypogammaglobulinemia, has long been considered a "wastebasket" category of primary immunodeficiencies that includes a number of immune disorders. However, a majority of the CVID individuals exhibit a distinctive phenotype characterized by normal numbers of immunoglobulin-bearing $B$ cell precursors and a broad deficiency of immunoglobulin isotypes $(1,5)$. We have proposed that this particular subset of CVID and IgA-D may represent polar ends of the spectrum, reflecting a common underlying genetic defect (6). This hypothesis is based on several lines of evidence. First, the cellular defect in both deficiencies consists of a failure of surface- $\mathrm{Ig}^{+} \mathrm{B}$ cells to undergo differentiation into antibody-secreting plasma cells $(3,5)$. Second, the two disorders occur in members of the same family (7). Third, IgA-D has been found associated with certain MHC haplotypes (8), and we have noted that the same MHC haplotypes are associated with both IgA-D and CVID (6). Finally, although the arrest in B cell differentiation is more extensive in CVID than in IgA-D, considerable overlap exists between the two. Some individuals with CVID produce substantial amounts of IgM, and conversely, some individuals with IgA-D are also deficient in IgG2 and IgG4 (9).

Initial studies on possible associations between $\operatorname{IgA}-\mathrm{D}$ and HLA antigens focused on MHC class I gene products. Several groups reported that IgA-D in patients with autoimmune and atopic diseases is associated with the HLA-A1, -A2, and -B8 antigens $(10,11)$. Subsequent investigations provided evidence for an association of IgA-D with a number of class I and/or class II HLA antigens, including A1, A28, B8, B14, B40, DR3, and DR7 (12-14), irrespective of associated diseases. An association with the haplotype HLA-A1, B8, and DR3 also became evident from these studies.

A report from Western Australia (8) provided the first indication that IgA-D may be associated with a gene (or genes) located within the MHC class III cluster in linkage disequilib- 
rium with class I and/or class II alleles. The class III MHC region occupies about $1,100 \mathrm{~kb}$ of DNA between the class I and the class II gene clusters (Fig. 1). 36 genes have now been mapped within this region, and most of these are expressed in a variety of cell types (15-17). Included are the genes encoding the complement proteins $\mathrm{C} 4 \mathrm{~A}, \mathrm{C} 4 \mathrm{~B}, \mathrm{C} 2$, and factor $\mathrm{B}$, the P450 enzyme 21-hydroxylase, the major heat-shock protein HSP70, and the tumor necrosis factors alpha (TNF $\alpha$ ) and beta. The function of the products of the remaining 25 genes in the region is currently unknown.

The proposed role of MHC class III gene(s) in the pathogenesis of IgA-D (18) was recently questioned by a report from Sweden, indicating a strong association between IgA-D and class II gene alleles (19). In a study of 95 IgA-D individuals, the authors identified three susceptibility and one protective DRDQ haplotypes. Susceptibility haplotypes had in common a neutral amino acid (Val or Ala) at residue 57 of the HLA-DQ
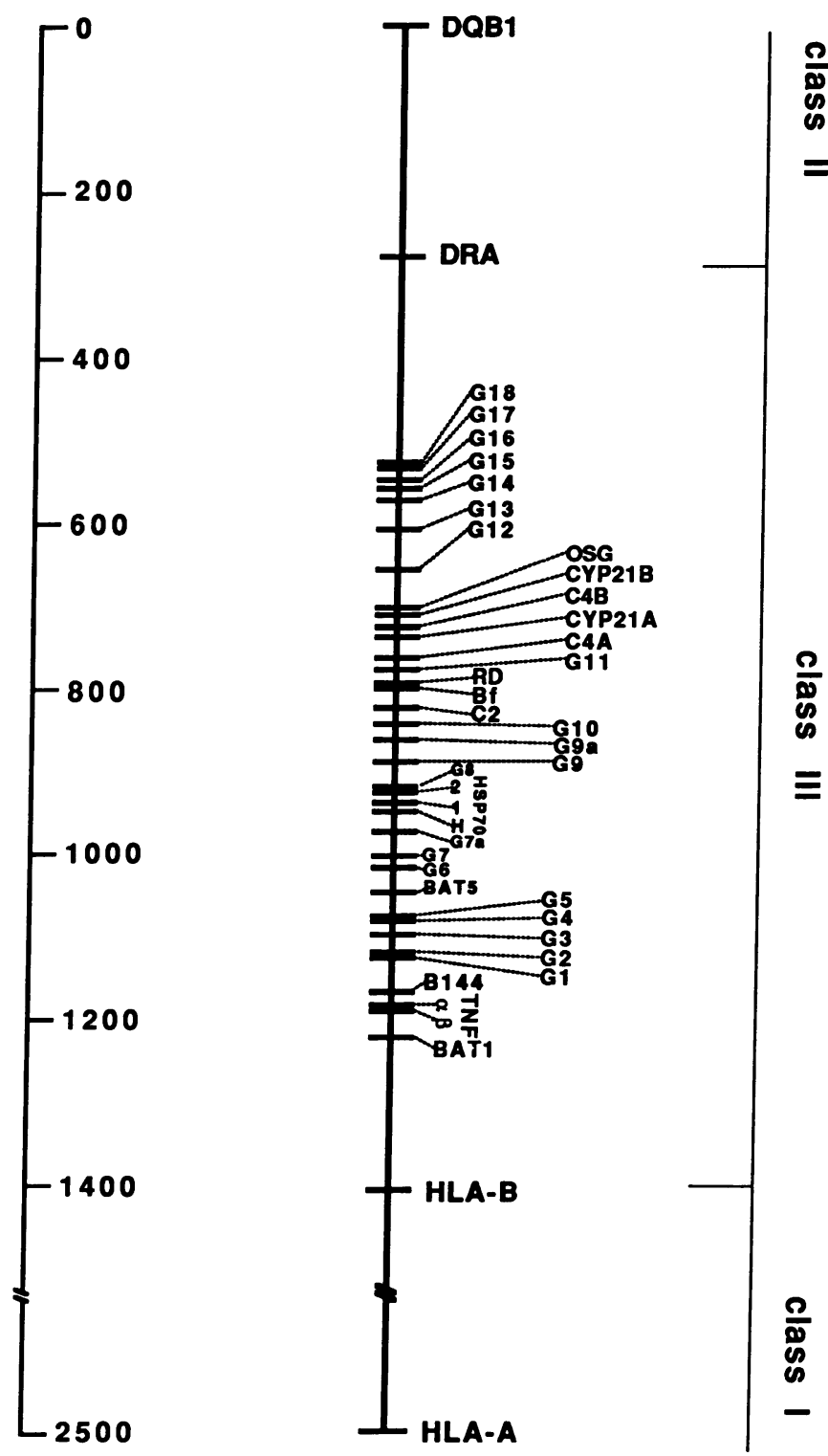

Figure 1. Map of the class III region of the human MHC. The approximate locations of the 36 genes mapped within this region (15, $16,17)$ are indicated. The class II and class I genes analyzed in this study are also shown. $\beta$-chain, whereas a negatively charged Asp residue at that position was found to be protective. It is of interest that the same amino acids at the same residue of the HLA-DQ $\beta$-chain had previously been reported to endow susceptibility to, or protection from, insulin-dependent diabetes mellitus (IDDM) $(20,21)$.

Previous studies from our group (6) indicated that individuals with IgA-D and CVID have in common a high incidence of C4A gene deletions and $\mathrm{C} 2$ rare gene alleles. These findings suggested that susceptibility to both immunodeficiencies may be determined by gene(s) within the class III region of the MHC. We have extended this analysis by defining the MHC haplotypes of IgA-D and CVID individuals and of their immediate relatives. The MHC haplotypes were defined by analyzing polymorphic markers for 11 genes or their products between the HLA-DQB1 and the HLA-A genes. The results indicate that a small number of MHC haplotypes are shared by the majority of immunodeficient individuals. They also provide further support for the hypothesis that a susceptibility gene or genes for large subsets of both IgA-D and CVID are located in the class III region of the MHC, possibly between the C4B and C2 genes.

\section{Methods}

Study population. 31 immunodeficient individuals (12 IgA-D and 19 CVID) from 21 families and 79 of their family members were included in the study. All subjects were Caucasian. 11 CVID and 5 IgA-D individuals were female. The clinical and immunologic parameters of all but five of the immunodeficient individuals have been reported previously (6). The five, previously unreported, immunodeficient individuals were members of the same family, and their clinical and immunologic parameters will be detailed in a separate report (Ashman, R. F., F. M. Schaffer, J. D. Kemp, W. M. Yokoyama, M. D. Cooper, and J. E. Volanakis, manuscript submitted for publication). All IgA-D and CVID individuals had normal numbers of circulating lymphocytes and normal distribution of $\mathrm{B}$ lymphocytes, as indicated by the percentages of $\mathrm{HB}^{+}, \mathrm{IgM}^{+}, \mathrm{IgD}^{+}$, and $\mathrm{IgA}{ }^{+}$cells. The mean $\pm \mathrm{SD}$ serum IgM, IgG, and IgA concentrations of the CVID individuals were $18 \pm 11,112 \pm 72$, and $8 \pm 11 \mathrm{mg} / \mathrm{dl}$, respectively. The corresponding values for the IgA-D individuals were $76 \pm 29,999 \pm 423$, and $7 \pm 5 \mathrm{mg} / \mathrm{dl}$. Normal laboratory ranges for IgM, IgG, and IgA are 45-226, 706-1,484, and 60-375 mg/ dl, respectively.

10 additional unrelated Caucasian subjects ( 8 female, 2 male) were also investigated. They were selected on the sole basis of homozygosity for the HLA-A1, B8, and DR3 haplotype from among the registrants of several HLA-typing laboratories.

Southern blot analysis. Genomic DNA was extracted from the buffy-coat fraction of blood samples collected in EDTA (22). $10 \mu \mathrm{g}$ of genomic DNA was digested with the appropriate restriction endonuclease under conditions recommended by the suppliers. DNA restriction fragments were separated by electrophoresis through $0.8-1.0 \%$ agarose gels. Phage $\lambda$ DNA digested with HindIII or with EcoRI plus HindIII were used as molecular size markers. After electrophoresis, DNA fragments were transferred to nitrocellulose membranes. Prehybridization and hybridization was then carried out by standard procedures (23). After hybridization, the membranes were washed under high stringency conditions and exposed to x-ray film. DNA fragments to be used as probes were isolated by electrophoresis in low-melting agarose and radiolabeled with [ $\left.{ }^{32} \mathrm{P}\right] \mathrm{dCTP}$ by the random primer method (24). Restriction enzymes, polymorphic fragments sizes, and probes for analyzing the restriction fragment length polymorphisms (RFLP) of the C4B, C4A, G11, C2, HSP-70, and TNF $\alpha$ genes are listed in Table I. Examples of the RFLP patterns for the $\mathrm{C} 4$ and $\mathrm{C} 2$ genes have been published from this laboratory (6). Examples of the RFLP patterns for the G11, HSP70, and TNF $\alpha$ genes are given in Fig. 2. 
Analysis of $B f$ gene alleles. A polymerase chain reaction (PCR)based procedure was developed for analyzing the MspI RFLP (38) of the $\mathrm{Bf}$ gene. The region between nucleotides -82 and 511 (39) was amplified by using two complementary oligonucleotides: 5'AAGTGATGTGGGTAGGACAGGC3' and 5'TGCAGTCTGCCTTCCTGACAGTCT 3'. Amplification was performed by using $1 \mu \mathrm{g}$ genomic DNA and 2.5 U DNA polymerase (Amplitaq; Perkin Elmer Cetus, Norwalk, CT). The PCR was carried out for 30 cycles in a TempCycler (Coy Laboratory Products, Ann Arbor, Michigan). Each cycle consisted of 1 min denaturation at $94^{\circ} \mathrm{C}, 2$ min annealing at $66^{\circ} \mathrm{C}$, and 2 min extension at $72^{\circ} \mathrm{C}$. The resulting 593-bp PCR product was digested with MspI and analyzed by agarose gel electrophoresis (Fig. 3). As shown, if the polymorphic MspI site is present, two fragments of $\sim 400$ and $200 \mathrm{bp}$ are seen. In the absence of the polymorphic site, a single $\sim 600$-bp fragment is present.

Analysis of $D Q B 1$ gene alleles. HLA-DQ $\beta$-chain alleles were analyzed by PCR amplification of the first domain of the $D Q \beta$-chain gene, followed by dot-blot analysis of the PCR product with allele-specific oligonucleotide probes. The oligonucleotides described by Morel et al. (21) were used for both PCR and hybridization. Allele-specific oligonucleotides were end labeled by using T4 polynucleotide kinase and $\gamma$ [ $\left.{ }^{32} \mathrm{P}\right]$ ATP. Dot blots, hybridization, and high-stringency washes were performed as described (21).

HLA typing. HLA-A, B, and DR typing was performed by the microdroplet lymphocytotoxicity assay as described previously (6).
Statistical Analysis. Differences in the frequency of study parameters between two populations were assessed by the chi-square test or when indicated by Fisher's exact test. An unbalanced analysis of variance (ANOVA) model with one main effect and three levels (40) was used to test differences in IgA concentrations among family members sharing zero, one, or two alleles identical by descent with IgA-D or CVID individuals. To test differences in the distribution of alleles identical by descent between affected and unaffected siblings of probands, the chi-square test with two degrees of freedom was applied. The statistical analysis system, release 6.03 (SAS Institute, Cary, NC), a software system for analysis of data, was used for all statistical analyses.

\section{Results}

16 of the 21 families studied had one immunodeficient member each, while the remaining 5 families had multiple immunodeficient members. Of the five multiplex families, one had five immunodeficient members, two had three each, and another two had two each (Fig. 4). Characteristically, all five of these families included both IgA-D and CVID members.

Polymorphic markers for 11 MHC genes spanning $\sim 2,500 \mathrm{~kb}$ of DNA were analyzed to define MHC haplotypes in the population. Of these 11 genes, 3 (HLA-A, -B, and -DR) were defined serologically at the protein level, while the re-

Table I. RFLPs of Class III MHC Genes

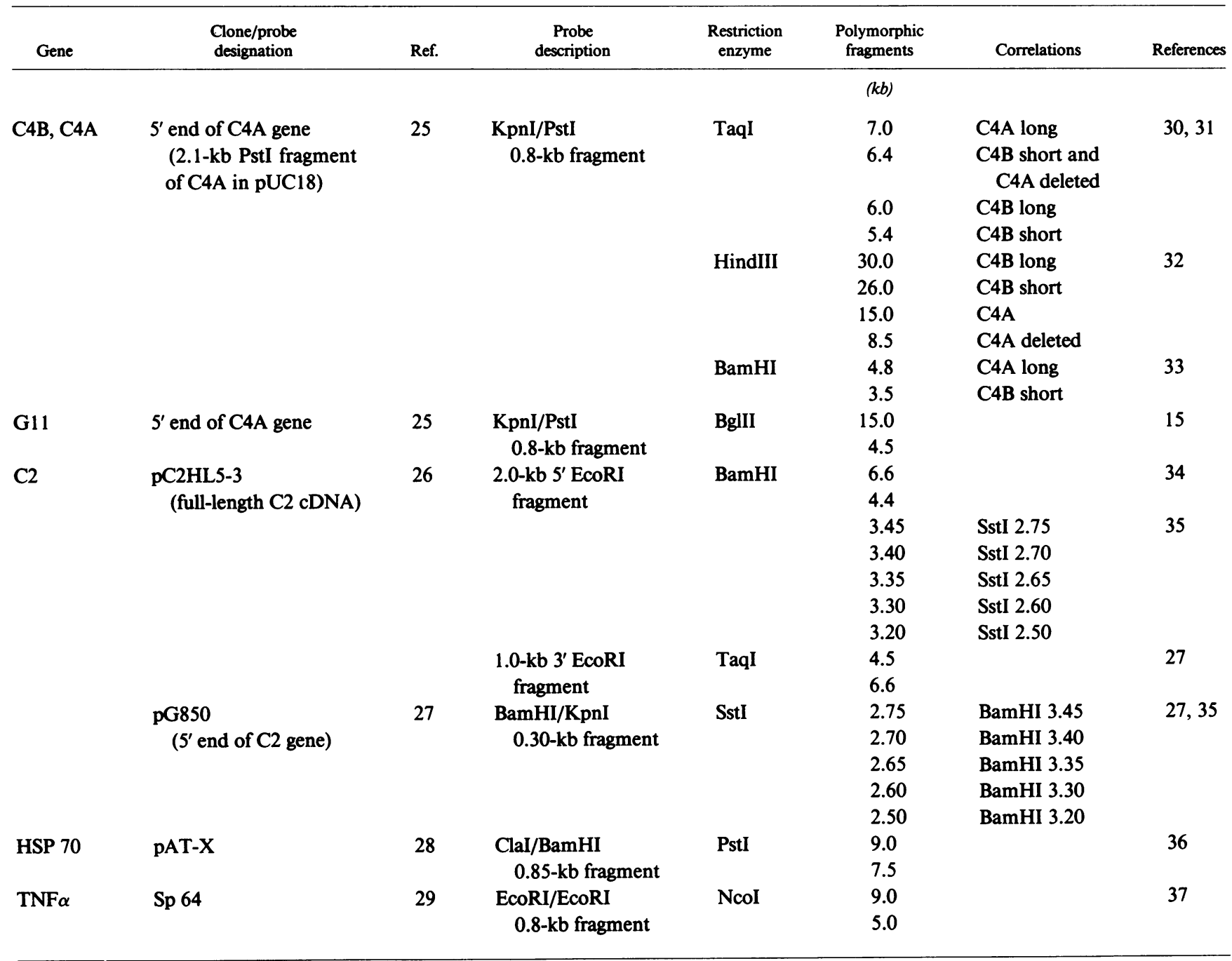




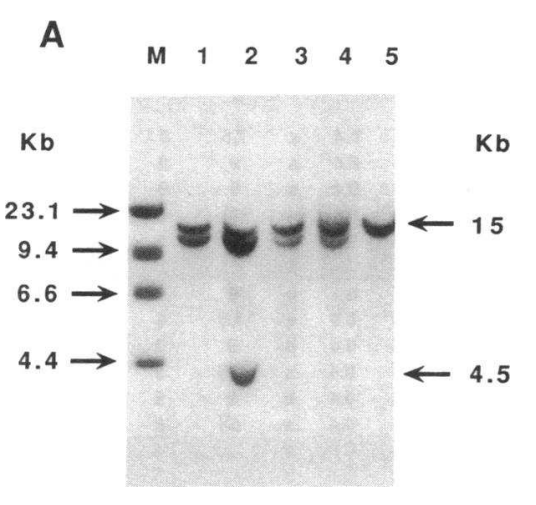

B
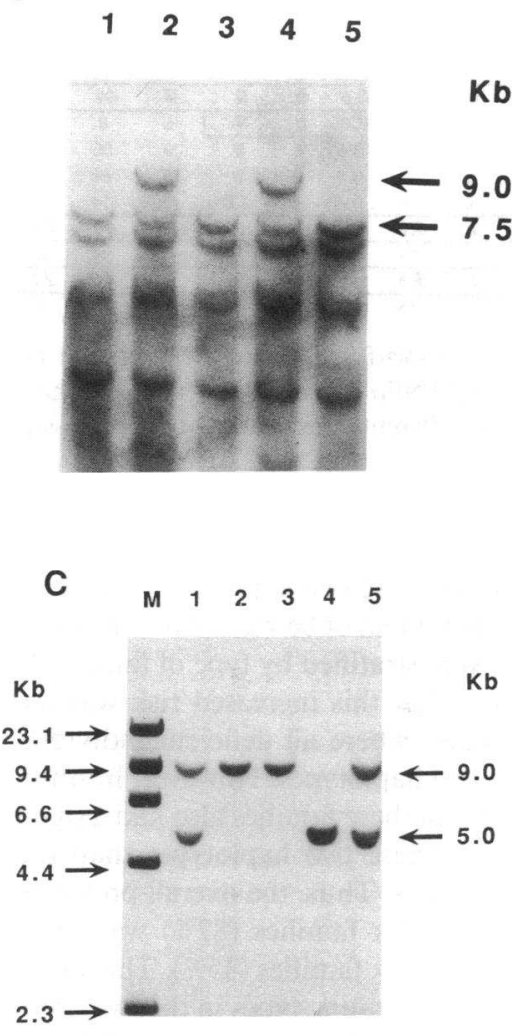

Kb

maining 8 were defined at the gene level. The procedure used for analyzing the HLA-DQ $\beta$ chain gene allows for the definition of nine distinct alleles (21). Of these, eight (DQB $1^{*} 0201$, ${ }^{*} 0301,{ }^{*} 0302,{ }^{*} 0303,{ }^{*} 0501,{ }^{*} 0502,{ }^{*} 0503$, and ${ }^{*} 0602$ ) were found among our study population. Three RFLPs of the C4 genes were analyzed by using TaqI, HindIII, and BamHI (Table I). They provided information on $\mathrm{C} 4$ gene deletions and/or duplications, and on C4B gene length. Four RFLPs of the C2 gene were analyzed by using SstI, BamHI, or TaqI restricted DNA (Table I). The combined results allowed for the definition of nine distinct haplotypes of the $\mathrm{C} 2$ gene, termed a to $i$ (35). Six of these (a, b, c, d, e, and i) were encountered among the study population. Single dimorphic RFLPs were used to analyze the G11, Bf, HSP-70, and TNF $\alpha$ genes.

Analysis of the data indicated that a small number of MHC haplotypes were shared by most immunodeficient individuals. Two of these, termed haplotype I (HLA-DQB1*0201, HLA-

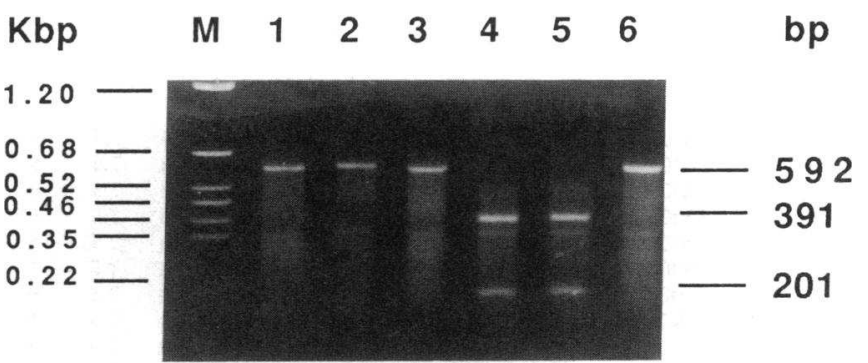

Figure 3. MspI RFLP of the Bf gene. A 593-bp region of the Bf gene between nucleotides -82 and 511 was amplified by PCR, the product was digested with MspI, and the resulting fragments were analyzed by agarose electrophoresis. (Lane $M$ ) size markers; (lanes $1,2,3,4$, $5,6)$ PCR products from genomic DNA of six individuals.

DR3, C4B-Sf, C4A-O, G11-15, Bf-0.4, C2-a, HSP-7.5, TNF $\alpha-$ 5, HLA-B8, HLA-A1) and haplotype II (HLA-DQB $1 * 0201$, HLA-DR7, C4B-S, C4A-L, G11-4.5, Bf-0.6, C2-b, HSP-9, TNF $\alpha-9$, HLA-B44, HLA-A29) were particularly interesting for several reasons. First, a CVID individual (F21-II.1; Figs. 4 and 5) was homozygous for haplotype I and an IgA-D individual (F06-II.1; Fig. 5) was homozygous for haplotype II. Second, these two haplotypes were encountered very frequently among
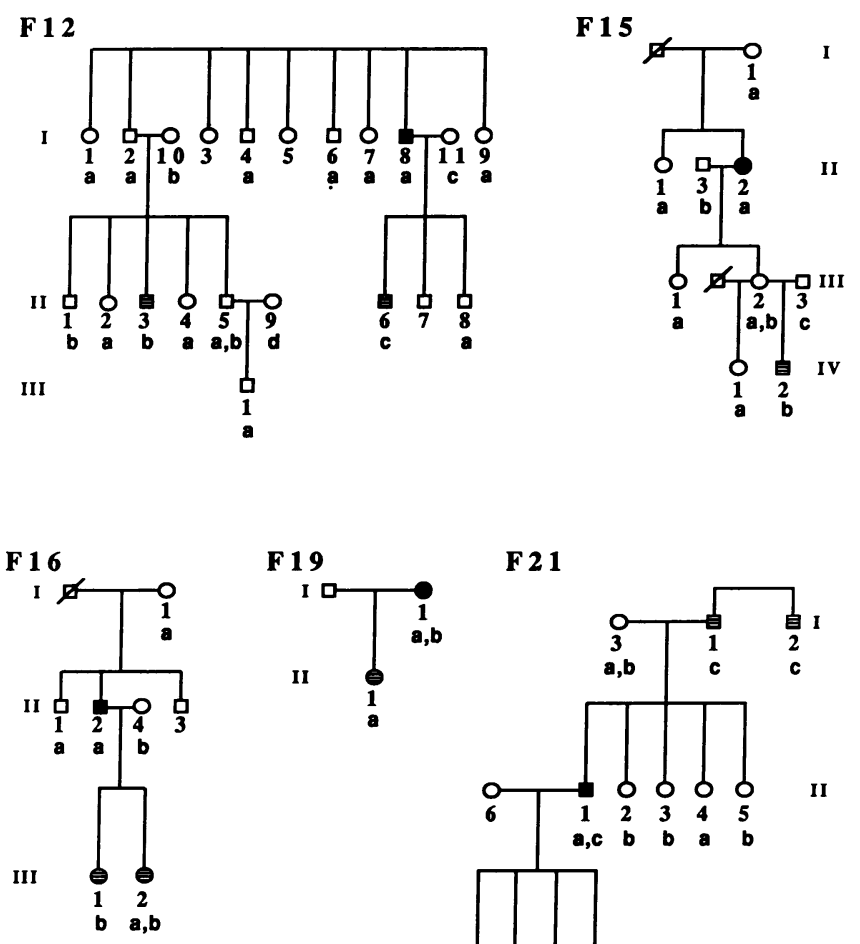

F 21

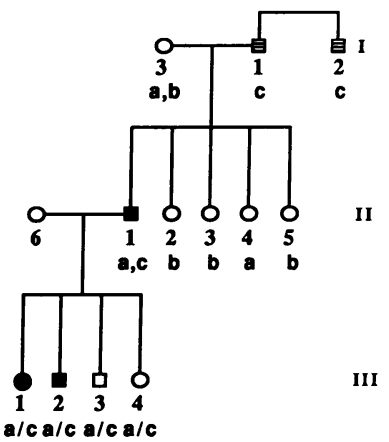

Figure 4. Trees of families containing more than one immunodeficient individual. Individuals with CVID are shown as solid symbols, and individuals with IgA-D with hatched symbols. A diagonal line through a symbol indicates the death of this individual. Within each family generations are numbered with roman numerals and individuals with arabic numbers. Lower case letters indicate haplotypes I or II as follows: (family 12) $a, b, c$, and $d$ haplotype I; (family 15) $a$ and $c$ haplotype $\mathrm{I}, b$, haplotype II; (family 16) $a$ and $b$, haplotype II; (family 19) $a$, haplotype I; (family 21) $a, b$, and $c$, haplotype I; $(a / c)$ haplotype I could be either $a$ or $c$. 


\begin{tabular}{ccc} 
FAM & ID & Dx \\
& & \\
& & \\
F08 & 11.1 & CVID \\
F15 & 11.2 & CVID \\
F10 & 1.1 & CVID \\
F12 & 1.8 & CVID \\
F19 & 1.1 & CVID \\
F21 & 11.1 & CVID \\
F21 & 11.1 & CVID \\
F21 & 1.1 & IgAD \\
F21 & 1.2 & IgAD \\
F12 & 11.3 & IgAD \\
F17 & 11.1 & IgAD \\
F19 & 11.1 & IgAD \\
F12 & 11.6 & IgAD \\
F21 & II.2 & CVID \\
F01 & 11.1 & CVID \\
F09 & 1.2 & CVID \\
F14 & 11.1 & CVID \\
F07 & 11.1 & IgAD \\
F02 & 11.1 & CVID \\
F20 & 11.2 & CVID \\
F03 & 11.2 & CVID \\
F16 & II.2 & IgAD \\
F04 & 1.1 & CVID \\
F15 & IV.2 & IgAD \\
F05 & 11.2 & CVID \\
F13 & 11.1 & CVID \\
F16 & 11.2 & CVID \\
F06 & 11.1 & IgAD \\
F18 & 11.2 & IgAD \\
F16 & 11.1 & IgAD \\
F11 & 1.1 & CVID \\
& & \\
\hline
\end{tabular}
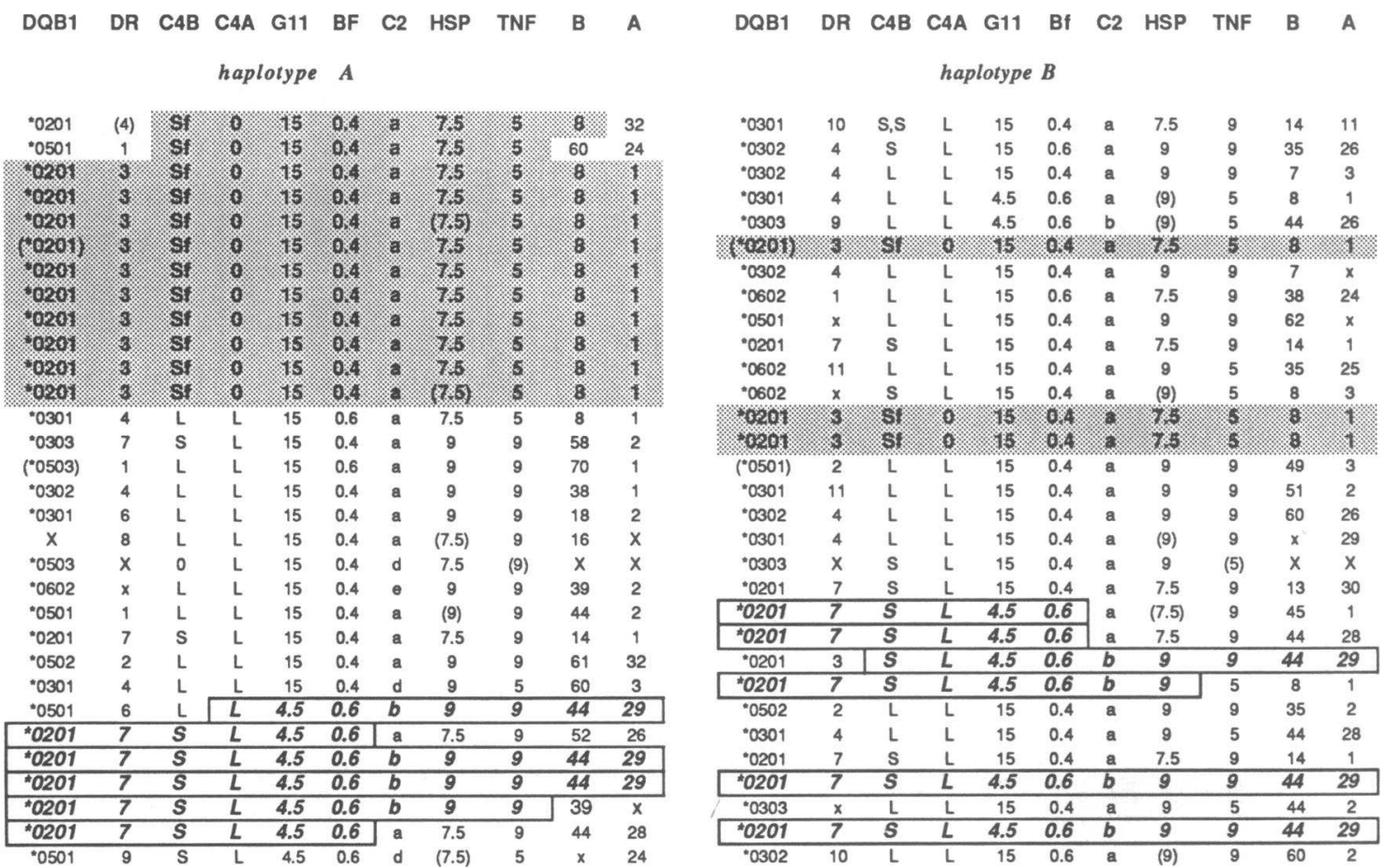

Figure 5. MHC haplotypes of IgA-D and CVID individuals. Alleles of the C4B gene are designated as $S f$, short-fused, $L$, long, $S$, short, or $O$, deleted. Alleles of the C4A gene are designated as $O$, deleted, or $L$, long; alleles for the G11, Bf, HSP70, and TNF $\alpha$ genes are designated by the length in kilobase of their polymorphic fragments; haplotypes of the $\mathrm{C} 2$ gene are designated as a to i (35). Parentheses indicate deduced assignment of allele; $x$, unknown allele.

the immunodeficient individuals. 15 copies of haplotype I were encountered among 14 immunodeficient individuals from seven families, and 12 copies of haplotype II in 10 immunodeficient individuals from eight families. Taken together, 24 of the 31 immunodeficient individuals $(77 \%)$ representing 14 of the 21 kindreds $(67 \%)$ had at least one of these two haplotypes. By comparison, 44 of the $79(56 \%)$ immunoglobulin sufficient family members had at least one of these haplotypes. The difference between the two groups is significant at the $P<0.04$ level. Third, there were no differences between IgA-D and CVID in terms of distribution of these two haplotypes. A third haplotype (HLA-DQB1*0201, HLA-DR7, C4B-S, C4A-L, G11-15, Bf-0.4, C2-a, HSP-7.5, TNF $\alpha-9$, HLA-B14, HLA-A1) was also found among these individuals, although less frequently than haplotypes I and II, being present in six immunodeficient individuals from five families.

The difference in the prevalence of haplotypes I and II be- tween immunoglobulin-deficient and -sufficient individuals indicated that carrying one of these two haplotypes leads to an approximately threefold higher risk of being immunoglobulindeficient. When the data were stratified by type of family (Table II), it became apparent that this increased risk was only evident in multiplex families, where all deficient individuals carried at least one of the two haplotypes. However, immunoglobulin-sufficient members of these families also had a significantly higher prevalence of these two haplotypes than their counterparts in simplex families. Thus, the overall prevalence of these haplotypes in multiplex families (82\%) was significantly higher than that in simplex families $(45 \%)$. This finding could be explained by different mating types in the two groups of families. Multiplex families probably represent (HNXHN) mating types $(\mathrm{H}$, high risk haplotype; $\mathrm{N}$, normal risk haplotype) which would lead to an expected value of $75 \%$ carriers of high risk haplotypes, whereas simplex families represent pre-

Table II. Distribution of Haplotypes I and II among Study Subjects

\begin{tabular}{|c|c|c|c|c|c|c|c|c|c|}
\hline \multirow{2}{*}{$\frac{\text { Haplotype }}{\text { I and/or II }}$} & \multicolumn{3}{|c|}{ Ig-deficient subjects } & \multicolumn{3}{|c|}{ Ig-sufficient subjects } & \multicolumn{3}{|c|}{ Total } \\
\hline & $\begin{array}{l}\text { Multiplex } \\
\text { families }\end{array}$ & $\begin{array}{l}\text { Simplex } \\
\text { families }\end{array}$ & Total & $\begin{array}{l}\text { Multiplex } \\
\text { families }\end{array}$ & $\begin{array}{l}\text { Simplex } \\
\text { families }\end{array}$ & Total & $\begin{array}{c}\text { Multiplex } \\
\text { families }\end{array}$ & $\begin{array}{l}\text { Simplex } \\
\text { families }\end{array}$ & Total \\
\hline Present & $15^{*}$ & $9^{\ddagger}$ & $24^{8}$ & $26^{\prime \prime}$ & 18 & 44 & $41^{\prime}$ & 27 & 68 \\
\hline Absent & 0 & 7 & 7 & 9 & 26 & 35 & 9 & 33 & 42 \\
\hline Total & 15 & 16 & 31 & 35 & 44 & 79 & 50 & 60 & 110 \\
\hline
\end{tabular}

* $P=0.006$ compared with Ig-deficient members of simplex families; $P=0.04$ compared with Ig-sufficient members of multiplex families Comparisons by using Fisher's exact test. ${ }^{\ddagger} P=0.29$ compared with Ig-sufficient members of simplex families $\left(\mathrm{x}^{2}=1.12\right)$. $P=0.035$ compared with Total Ig-sufficient individuals $\left(\mathrm{x}^{2}=4.45\right)$. " $P=0.003$ compared with Ig-sufficient members of simplex families $\left(\mathrm{x}^{2}=8.80\right)$. $P<$ 0.001 compared with members of simplex families $\left(x^{2}=15.82\right)$. 
dominantly (HNXNN) mating types leading to a corresponding value of $50 \%$.

Not all kindreds had these haplotypes conserved in their entirety, but in all cases six or more contiguous polymorphic markers were conserved, spanning at least $500 \mathrm{~kb}$ of DNA. Haplotype I was conserved in its entirety in 12 of 14 individuals (five of seven families; Fig. 5). This haplotype is characterized by a deletion involving the major part of the C4A gene, the entire $21 \mathrm{OH}-\mathrm{A}$ gene, and the $5^{\prime}$ most region of a short $\mathrm{C} 4 \mathrm{~B}$ gene (32). All 10 HLA-A1, B8, DR3 homozygous unrelated individuals included in the study had the complete haplotype I. 2 of these 10 individuals, both female, had serum IgA concentration of less than $7 \mathrm{mg} / \mathrm{dl}$. The serum IgA concentration of the remaining eight subjects was between 130 and $346 \mathrm{mg} / \mathrm{dl}$. The serum IgM and IgG concentrations of all 10 individuals were within normal limits. Data from the HLA typing lab of this university suggest a frequency of 0.120 for this haplotype among the population of this area. Haplotype II was less well conserved and is characterized by the $0.6-\mathrm{Kb}$ MspI fragment of the $\mathrm{Bf}$ gene in association with a $\mathrm{b}$ haplotype of the $\mathrm{C} 2$ gene. No informative crossovers of these MHC haplotypes were observed within any of the kindreds in this study. This finding is not surprising, given the relatively small size of the sample and the overall low frequency of recombination within the MHC (41).

In view of a recent report (19) indicating that a noncharged amino acid at residue 57 of the DQ $\beta$-chain represents a major susceptibility factor for IgA-D, we analyzed our data for the presence of DQ $\beta$-chain alleles displaying either Asp or a neutral amino acid at position 57. The results (Fig. 6) indicate that there is no difference between immunoglobulin-deficient and -sufficient individuals among our study population in terms of the distribution of the two types of DQ $\beta$-chain alleles. The distribution of these alleles among the individuals investigated

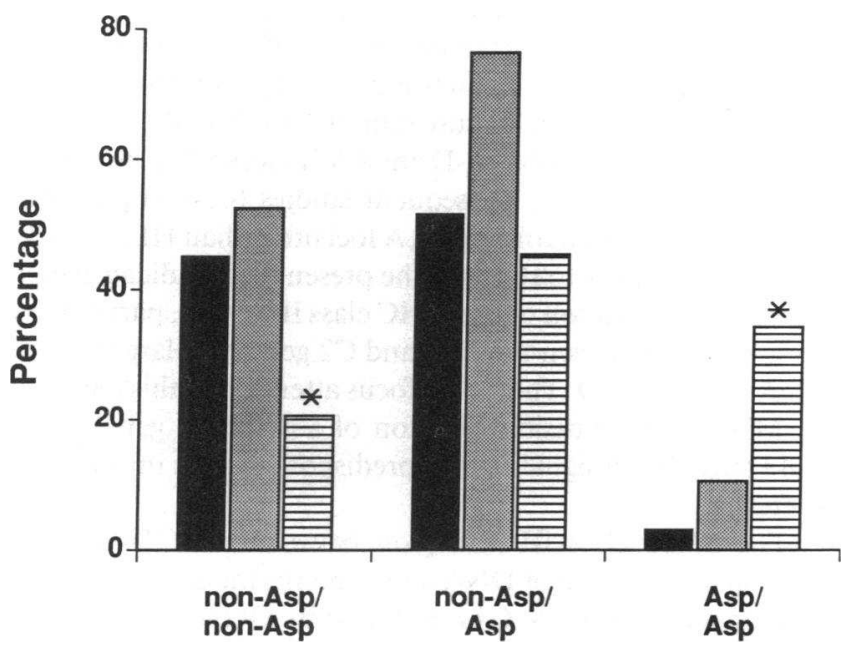

Figure 6. Distribution of HLA-DQ $\beta$-chain alleles among 31 immunodeficient individuals, 76 of their immunoglobulin-sufficient relatives, and 223 unrelated healthy controls. Non-Asp, neutral amino acid (Valine, Alanine, or Serine) at position 57 of the DQ $\beta$ chain; Asp, aspartic acid at position 57. Normal controls are taken from two previously published studies $(19,21)$. *Statistically significant differences $(P<0.008)$ between the controls and both other groups. $m$, Igsufficient; $\mathbf{a}$, Ig-deficient; $\mathbf{a}$, controls. in this study was also compared with that among 223 unrelated healthy individuals taken from the literature. 100 of these normal control individuals were from Sweden (19) and the remaining 123 from Pennsylvania (21). The two groups had very similar distributions of Asp/non-Asp residues at position 57 of the $\mathrm{DQ} \beta$-chain. As shown in Fig. 6, the frequencies of homozygous non-Asp/non-Asp or Asp/Asp DQ $\beta$-chain alleles observed among our immunoglobulin deficient group was significantly different from those of the control group. Significant differences were also found when the group of immunoglobulin-sufficient relatives was compared with the controls. The $45 \%$ frequency of non-Asp/non-Asp individuals among the immunoglobulin deficient group of this study was considerably lower than the $62 \%$ reported by Olerup et al. (19). However, the difference was not statistically significant.

To test the hypothesis that the degree of haplotype sharing has a significant effect on IgA levels, an ANOVA unbalanced design model was used. The number of alleles shared by siblings with the proband was the single main effect tested. The results indicated that there is no effect of the number of alleles identical by descent on the IgA levels. The data were also analyzed for differences in the frequency distribution of affected and normal siblings in the three classes of identity by descent $(2,1,0)$, representing the number of alleles shared with the proband. Differences between the classes, i.e., changing the continuous levels to dichotomous, low, or normal scores, were tested. Low values were those that fell into the lower decile of the distribution. No association between number of alleles identical by descent and IgA levels was found.

\section{Discussion}

The most remarkable finding of this study was that a small number of MHC haplotypes were encountered repeatedly among CVID and IgA-D individuals from different families. At least one copy of one of two of these haplotypes was present in the genome of 24 of the 31 immunodeficient individuals studied. This finding is in sharp contrast to the clinical heterogeneity of both IgA-D and CVID. No differences were observed between CVID and IgA-D in terms of distribution of these haplotypes, which is consistent with a shared defect for these two conditions. The presence of both CVID and IgA-D individuals among all five multiplex families also lends strong support to the proposal that these two defects may have a common genetic basis.

Although all immunodeficient individuals in the five multiplex families had at least one copy of haplotype I or II; interestingly, within the same family these haplotypes often were not identical by descent. Family 12 (Fig. 4) provides the clearest example of this observation. The CVID individual of this family (F12-I.8, Figs. 4 and 5) inherited haplotype I from one of his parents, but his IgA-D son (F12-II.6) inherited the same haplotype from his mother. The second IgA-D member of this family (F12-II.3) also inherited this haplotype from his mother, who is unrelated to individual F12-I.8 (Fig. 4). Thus, all three immunodeficient individuals of this large family have a copy of haplotype I, but each one of them inherited it through a different line of descent. Formal confirmation of this finding was provided by the statistical analysis of the entire data set, which found no association between the number of alleles identical by descent and serum IgA concentration. These observations provide further support to the proposed association of IgA-D and 


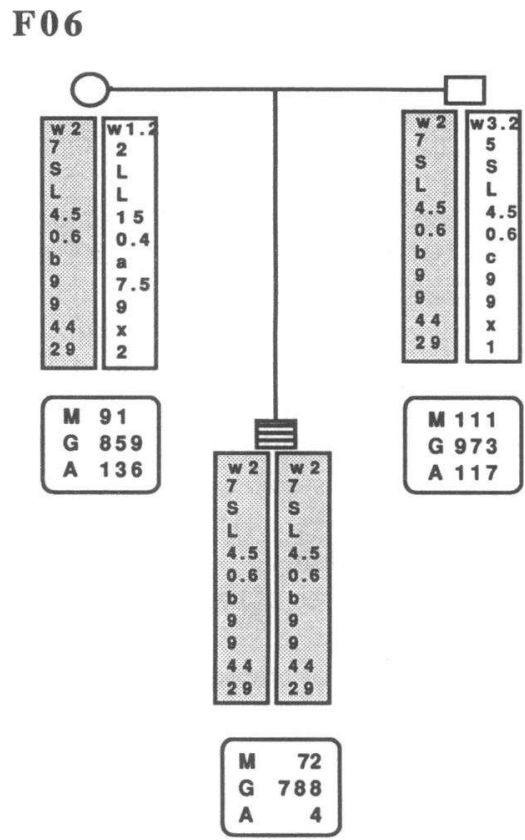

Figure 7. Example of possible autosomal recessive inheritance of IgA-D. The IgA-D son inherited haplotype II from both of his parents. Alleles of the genes listed in Fig. 5 are given. Levels of $\operatorname{IgM}(M)$, IgG $(G)$, and $\operatorname{IgA}(A)$ are given for each individual in $\mathrm{mg} / \mathrm{dl}$.

CVID with particular MHC haplotypes, which are relatively common in the population (18).

Analysis of the family data provided insufficient information to assign the mode of inheritance of IgA-D and CVID. An example of a possible autosomal recessive mode of inheritance was provided by family 6 (Fig. 7). The IgA-D son (F06.II.1, Fig. 5) inherited a copy of haplotype II from each of his parents, both of whom had normal serum immunoglobulin concentrations. In other families, an autosomal dominant mode could best explain the pattern of inheritance. A more constant finding was the presence of family members, including siblings, who were MHC identical, but discordant for immunodeficiency. A clear example of this observation is given by the large kindred F21, shown in Fig. 4. Of the four siblings in generation III, two, III.1 and III.2, had CVID, while the other two had normal serum immunoglobulin levels. Yet, III.1 had identical MHC haplotypes with her brother, III.3, and III. 2 had identical haplotypes with his sister, III.4. Furthermore, 12 of the 13 members investigated in this family had at least one copy of haplotype I (Fig. 4), but only 5 of these had immunodeficiency. Similarly, in Family 12 (Fig. 4), 17 of the 21 members analyzed had a copy of haplotype I, but only 3 of these had immunodeficiency. Finally, among the 10 healthy unrelated individuals selected on the basis of homozygosity for haplotype I, only 2 were found to be IgA-D. These combined results indicate that the presence of these MHC haplotypes is not a sufficient condition for expression of IgA-D or CVID. However, given the distribution of haplotypes I and II among unrelated IgA-D and CVID individuals, it seems likely that their presence is a necessary condition for expression of these disorders by the majority of affected individuals.

Although no informative crossovers of the MHC haplotypes were observed within any of the kindreds in this study, it seems plausible that the partially conserved haplotypes I and II (Fig. 5) resulted from crossover events occurring in the past between each of these two haplotypes and unrelated MHC haplotypes. If this assumption is correct, inspection of the con-

served regions of the two haplotypes indicates that the putative susceptibility gene or genes are located within the class III region of the MHC (Fig. 1). This conservative estimate is based on haplotype A of the CVID individuals F08.II.1 and F15.II.2 (Fig. 5). Both of these haplotypes have identical alleles with haplotype I throughout the class III region but not the class II or class I regions of the MHC. Similarly, haplotype B of the CVID individual F04.I.1 and haplotype A of the IgA-D individual F18.II.2 share identical class III region alleles with haplotype II (Fig. 5). A comparison of haplotype A of individual F05.II.2 and haplotype B of F15.IV.2 shows that they share the class III subregion of haplotype II between the C4B and the TNF $\alpha$ genes. A less conservative estimate, derived from comparison of haplotype A of F05.II.2 with haplotypes A of F13.II.1, A of F16.II.1, B of F16.III.2, or B of F03.II.2 (Fig. 5), suggests that the putative susceptibility gene or genes are located between the genes encoding $\mathrm{C} 4 \mathrm{~B}$ and $\mathrm{C} 2$.

The arrested $B$ cell differentiation, involving varying combinations of B cell isotypes in CVID and IgA-D individuals, could be due to an inherent $B$ cell defect, a genetic defect primarily affecting $T$ cells, or one affecting the cooperative interaction between $\mathrm{T}$ and $\mathrm{B}$ cells necessary for normal antibody responses. While none of these possibilities can be easily excluded by the presently available data, it is notable that $T$ cell defects have been an inconsistent feature in CVID and IgA-D individuals $(42,43)$. In fact, integrity of helper $T$ cell function for mitogen-induced B cell responses of all isotypes is the rule in these patients, as was demonstrated for affected members in Family 21 (Fig. 4) of the present study (Ashman, R. F., F. M. Schaffer, J. D. Kemp, W. M. Yokoyama, M. D. Cooper, and J. E. Volanakis, manuscript submitted for publication). The possibility of defective $T$ and $B$ cell interactions is more diffcult to exclude, and it is within this context that the proposal of a predisposing MHC class II gene (19) becomes attractive.

Our results on the distribution of $\mathrm{DQ} \beta$ chain alleles displaying Asp or non-Asp residues at position 57 are not signifcantly different from those of the Swedish investigators who suggested that this amino acid could be imparting susceptibility to IgA-D (19). The presence or absence of an Asp residue at position 57 of the DQ $\beta$-chain was originally found to correlate strongly with resistance or susceptibility to $\operatorname{IDDM}(20,21)$, a disorder that shares with IgA-D and CVID some, but not other, MHC haplotypes (44). Subsequent studies (45-47) provided evidence suggesting a role for HLA loci other than HLA-DQB1 in the susceptibility to IDDM. The present data indicate a high degree of conservation of the MHC class III region, particularly the subregion between the $\mathrm{C} 4 \mathrm{~B}$ and $\mathrm{C} 2$ genes, for large subsets of IgA-D and CVID. Thus, they focus attention to this region of the MHC as the possible location of a defective gene(s) that could affect $B$ cell signaling and predispose to both immunodeficiencies.

The MHC class III subregion between the C4B and C2 genes spans $\sim 75-\mathrm{kb}$ of DNA and contains the genes CYP45021 hydroxylase $A, C 4 A, G 11, R D$, and Bf. Of these, the first is a pseudogene. The C4A gene deserves special consideration and is discussed below. The structure and function of the product of the G11 gene are unknown. The RD gene, first identified in the mouse $\mathrm{H}-2 \mathrm{MHC}$, is transcribed in all tissues so far examined (48). The amino acid sequence deduced from the cDNA represents a 42-kD polypeptide and lacks a typical leader peptide, indicating a housekeeping protein. The primary sequence is characterized by a unique 52 amino acid residue region com- 
posed entirely of the repeating dipeptide Arg-Asp. In the mouse, Lys residues substitute for some of the Arg and Glu for some of the Asp. We have cloned and sequenced the human cDNA for RD that displays only Arg residues within the repeat region. The $\mathrm{Bf}$ gene encodes the complement protein, factor $\mathrm{B}$, an essential component of the alternative pathway. Both the gene and the protein structure of factor $B$ are known $(49,50)$. Factor $B$ is polymorphic with two common alleles, $F$ and $S$, two less common alleles, $F_{1}$ and $S_{1}$, and up to 14 very rare alleles (51). No functional differences among these alleles have been described.

C4A and C4B encode the two isotypes of the fourth component of human complement. Comparison of the $C 4 A$ and $C 4 B$ cDNA sequences has revealed a greater than $99 \%$ homology (52). Of the 14 nucleotide differences, 12 are clustered on the $\mathrm{C} 4 \mathrm{~d}$ region and cause nine amino acid substitutions. Despite their striking homology, C4A and C4B exhibit markedly different reactivities. Upon activation by $\mathrm{Cls}$, the $\mathrm{C} 4 \mathrm{~b}$ fragment of C4A forms preferentially amide bonds with free amino $\left(-\mathrm{NH}_{2}\right)$ groups by a transacylation reaction involving a metastable thioster bond. In contrast, C4B forms preferentially ester bonds with hydroxyl $(-\mathrm{OH})$ groups of carbohydrate residues (53). Thus, the C4A isotype is thought to be primarily involved in the formation of the classical pathway $\mathrm{C} 3$ convertase on the surface of antigen-antibody complexes, whereas the C4B isotype to be mainly responsible for assembly of the $\mathrm{C} 3$ convertase on the surface of bacterial cells.

The different reactivities of the two isotypes of $\mathrm{C} 4$ may have implications for the development and maturation of immune responses to soluble antigens. Studies in animals have demonstrated that inherited or experimentally induced deficiencies of components of the classical pathway, including $\mathrm{C} 4$, are associated with diminished immune responses to $T$ dependent and independent antigens (54). Immune responses of these complement deficient animals are characterized by decreased primary and secondary responses and by defective isotype switching during secondary responses. In addition, humans with similar deficiencies have low serum concentration of IgG4 (55), suggesting defective isotype switching. Proposed mechanisms for complement participation in the regulation of antibody responses involve signal transduction by $\mathrm{C} 4$ and $\mathrm{C} 3$ activation fragments through the CR1 and CR2 receptors on the surface of B cells (56). CR1 binds C4b, C3b, and iC3b, whereas CR2 binds $\mathrm{iC} 3 \mathrm{~b}$ and $\mathrm{C} 3 \mathrm{dg}$. Production of these fragments by antigen-antibody complexes requires an intact classical complement pathway. Recent experiments have demonstrated (57) that a recombinant, soluble CR2, that competed with cellular $\mathrm{CR} 1$ for $\mathrm{C} 3 \mathrm{dg}$ binding suppressed $\mathrm{T}$ cell-dependent responses in mice. These considerations suggest a possible link between the C4A gene deletion characterizing haplotype I and the resulting susceptibility to IgA-D/CVID associated with this haplotype.

Two additional facts bear on this discussion. First, there are more than 10 allotypes of each $\mathrm{C} 4$ isotype (52). Teleological considerations would suggest that $\mathrm{C} 4$ allotypes express differential functional activities, imparting selective evolutionary advantages similar to those attributed to MHC class I and II allotypes. In fact, subtle differences among $\mathrm{C} 4$ allotypes were hypothesized to underly autoimmune diseases (58). However, with the exception of the C4A6 allotype, which cannot support the assembly of a C5-convertase (59), functional differences among C4 allotypes have not been reported. Second, substitu- tion of a single Asp for His at position 1106 by site-directed mutagenesis converted $\mathrm{C} 4 \mathrm{~B}$ to $\mathrm{C} 4 \mathrm{~A}$ in terms of functional activity (60). It seems possible that similar mutations in the $\mathrm{C} 4 \mathrm{~A}$ gene associated with IgA-D/CVID risk haplotypes may result in attenuated function. Current studies aim at investigating this possibility.

\section{Acknowledgments}

We thank Dr. David Chaplin, Washington University, St. Louis, for providing the C4 DNA probe, and Dr. J. F. Kaumeyer, Genentech, Inc., South San Francisco, for providing the plasmid Sp64. The skilled secretarial assistance of Mrs. Paula Kiley is gratefully acknowledged.

This work was supported in part by United States Public Health Service grants AR03555, AI23694, and CA13148. M. D. Cooper is a Howard Hughes Medical Institute investigator.

\section{References}

1. Eibl, M., C. Griscelli, M. Seligmann, F. Aiuti, T. Kishimoto, S. Matsumoto, L. A. Hanson, W. H. Hitzig, R. A. Thompson, M. D. Cooper, et al. 1989. Primary immunodeficiency diseases: report of a WHO Sponsored Meeting. Immunodefic. Rev. 1:173-205.

2. Schaffer, F. M., R. C. Monteiro, J. E. Volanakis, and M. D. Cooper. 1991. IgA Deficiency. Immunodefic. Rev. 3:15-44.

3. Conley, M. E., and M. D. Cooper. 1981. Immature IgA B cells in IgA-deficient patients. $N$. Engl. J. Med. 305:495-497.

4. Gathings, W. E., A. R. Lawton, and M. D. Cooper. 1977. Immunofluorescent studies of the development of pre-B cells, B lymphocytes and immunoglobulin isotype diversity in humans. Eur. J. Immunol. 7:804-810.

5. Cooper, M. D., A. R. Lawton, and D. E. Bockman. 1971. Agammaglobulinaemia with B lymphocytes. Specific defect of plasma-cell differentiation. Lancet. ii:791-794.

6. Schaffer, F. M., J. Palermos, Z. B. Zhu, B. O. Barger, M. D. Cooper, and J. E. Volanakis. 1989. Individuals with IgA deficiency and common variable immunodeficiency share polymorphisms of major histocompatibility complex class III genes. Proc. Natl. Acad. Sci. USA. 86:8015-8019.

7. Wollheim, F. A., and R. C. Williams, Jr. 1965. Immunoglobulin studies in six kindreds of patients with adult hypogammaglobulinemia. J. Lab. Clin. Med. 66:433-445.

8. Wilton, A. N., T. J. Cobain, and R. L. Dawkins. 1985. Family studies in IgA deficiency. Immunogenetics. 21:333-342.

9. Oxelius, V. A., A. B. Laurell, B. Lindquist, H. Golebiowska, U. Axelsson, J. Björkander, and L. A. Hanson. 1981. IgG subclasses in selective IgA deficiency: importance of IgG2-IgA deficiency. N. Engl. J. Med. 304:1476-1477.

10. Ambrus, M., E. Hernadi, and G. Bajtai. 1977. Prevalence of HLA-A1 and HLA-B8 antigens in selective IgA deficiency. Clin. Immunol. Immunopathol. 7:311-314.

11. Østergaard, P. A., and J. Eriksen. 1979. Association between HLA-A1 B8 in children with extrinsic asthma and IgA deficiency. Eur. J. Pediatr. 131:263270 .

12. Oen, K., R. E. Petty, and M. L. Schroeder. 1982. Immunoglobulin A deficiency: genetic studies. Tissue Antigens. 19:174-182.

13. Hammarström, L., and C. I. E. Smith 1983. HLA-A, B, C and DR antigens in immunoglobulin A deficiency. Tissue Antigens. 21:75-79.

14. Hammarström, L., U. Axelsson, J. Björkander, L. A. Hanson, E. Möller, and C. I. E. Smith. 1984. HLA antigens in selective IgA deficiency: distribution in healthy donors and patients with recurrent respiratory tract infections. Tissue Antigens. 24:35-39.

15. Sargent, C. A., I. Dunham, and R. D. Campbell. 1989. Identification of multiple HTF-island associated genes in the human major histocompatibility complex class III region. EMBO (Eur. Mol. Biol. Organ.) J. 8:2305-2312.

16. Spies, T., G. Blanck, M. Bresnahan, J. Sands, and J. L. Strominger. 1989. A new cluster of genes within the human major histocompatibility complex. Science (Wash. DC) 243:214-217.

17. Kendall, E., C. A. Sargent, and R. D. Campbell. 1990. Human major histocompatibility complex contains a new cluster of genes between the HLA-D and complement C4 loci. Nucleic Acids Res. 18:7251-7257.

18. French, M. A. H., and R. L. Dawkins. 1990. Central MHC genes, IgA deficiency and autoimmune disease. Immunol. Today. 11:271-274.

19. Olerup, O., C. I. E. Smith, and L. Hammarström. 1990. Different amino acids at position 57 of the HLA-DQ $\beta$ chain associated with susceptibility and resistance to IgA deficiency. Nature (Lond.). 347:289-290.

20. Todd, J. A., J. I. Bell, and H. O. McDevitt. 1987. HLA-DQ $\beta$ gene contributes to susceptibility and resistance to insulin-dependent diabetes mellitus. $\mathrm{Na}$ ture (Lond.). 329:599-604 
21. Morel, P. A., J. S. Dorman, J. A. Todd, H. O. McDevitt, and M. Trucco. 1988. Aspartic acid at position 57 of the HLA-DQ $\beta$ chain protects against type diabetes: A family study. Proc. Natl. Acad. Sci. USA. 85:8111-8115.

22. Sykes, B. C. 1983. DNA in heritable disease. Lancet. ii:787-788.

23. Meinkoth, J., and G. Wahl. 1984. Hybridization of nucleic acids immobilized on solid supports. Anal. Biochem. 138:267-284.

24. Feinberg, A. P., and B. Vogelstein. 1983. A technique for radiolabeling DNA restriction endonuclease fragments to high specific activity. Anal. Biochem. 132:6-13.

25. White, P. C., D. Grossberger, B. J. Onufer, D. D. Chaplin, M. I. New, B Dupont, and J. L. Strominger. 1985. Two genes encoding steroid 21-hydroxylase are located near the genes encoding the fourth component of complement in man. Proc. Natl. Acad. Sci. USA. 82:1089-1093.

26. Horiuchi, T., K. J. Macon, V. J. Kidd, and J. E. Volanakis. 1989. cDNA coning and expression of human complement component $\mathrm{C}^{2}$ J. Immunol. 142:2105-2111.

27. Bentley, D. R., R. D. Campbell, and S. J. Cross. 1985. DNA polymorphism of the $\mathrm{C} 2$ locus. Immunogenetics. 22:377-390.

28. Sargent, C. A., I. Dunham, J. Trowsdale, and R. D. Campbell. 1989. Human major histocompatibility complex contains genes for the major hea shock protein HSP70. Proc. Natl. Acad. Sci. USA. 86:1968-1972.

29. Pennica, D., G. E. Nedwin, J. S. Hayflick, P. H. Seeburg, R. Derynck, M. A. Palladino, W. J. Kohr, B. B. Aggarwal, and D. V. Goeddel. 1984. Human tumour necrosis factor: precursor structure, expression and homology to lymphotoxin. Nature (Lond.) 312:724-729.

30. Schneider, P. M., M. C. Carroll, C. A. Alper, C. Rittner, A. S. Whitehead E. J. Yunis, and H. R. Colten. 1986. Polymorphism of the human complemen C4 and steroid 21-hydroxylase genes. Restriction fragment length polymorphisms revealing structural deletions, homoduplications, and size variants. $J$. Clin. Invest. 78:650-657.

31. Yu, C. Y., and R. D. Campbell. 1987. Definitive RFLPs to distinguish between the human complement $\mathrm{C4A} / \mathrm{C} 4 \mathrm{~B}$ isotypes and the major Rodgers/ Chido determinants: application to the study of $\mathrm{C} 4$ null alleles. Immunogenetics. 25:383-390.

32. Carroll, M C., A. Palsdottir, K. T. Belt, and R. R. Porter 1985. Deletion of complement $\mathrm{C} 4$ and steroid 21-hydroxylase genes in the HLA class III region. EMBO (Eur. Mol. Biol. Organ.) J. 4:2547-2552.

33. Belt, K. T., C. Y. Yu, M. C. Carroll, and R. R. Porter. 1985. Polymorphism of human complement component C4. Immunogenetics. 21:173-180.

34. Woods, D. E., M. D. Edge, and H. R. Colten. 1984. Isolation of a complementary DNA clone for the human complement protein $\mathrm{C} 2$ and its use in the identification of a restriction fragment length polymorphism. J. Clin. Invest. 74:634-638

35. Zhu, Z. B., and J. E. Volanakis. 1990. Allelic associations of multiple RFLPs of the gene encoding complement protein C2. Am. J. Hum. Genet. 46:956-962.

36. Ratanachaiyavong, S., A. G. Demaine, R. D. Campbell, and A. M McGregor. 1991. Heat shock protein 70 (HSP70) and complement C4 genotypes in patients with hyperthyroid Graves' disease. Clin. Exp. Immunol. 84:48-52.

37. Dawkins, R. L., A. Leaver, P. U. Cameron, E. Martin, P. H. Kay, and F. T. Christiansen. 1989. Some disease-associated ancestral haplotypes carry a polymorphism of TNF. Hum. Immunol. 26:91-97.

38. Morley, B. J., and R. D. Campbell. 1984. Internal homologies of the Ba fragment from human complement component factor B, a class III MHC antigen. EMBO (Eur. Mol. Biol. Organ.) J. 3:153-157.

39. Wu, L.-C., B. J. Morley, and R. D. Campbell. 1987. Expression of the human protein factor $\mathrm{B}$ gene: evidence for the role of two distinct $5^{\prime}$ flanking elements. Cell. 48:331-342.

40. Snedecor, G. W., and W. G. Cochran. 1967. Statistical Methods, 6th edition. Iowa State Press, Ames, Iowa. 285-298.
41. Awdeh, Z. L., D. Raum, E. J. Yunis, and C. A. Alper. 1983. Extended HLA/complement allele haplotypes: evidence for T/t-like complex in man. Proc Natl. Acad. Sci. USA. 80:259-263.

42. de la Concha, E. G., G. Oldham, A. D. Webster, G. L. Asherson, and T. A Platts-Mills. 1977. Quantitative measurements of T- and B-cell function in "variable" primary hypogammaglobulinaemia: evidence for a consistent B-cell defect. Clin. Exp. Immunol. 27:208-215.

43. Waldmann, T. A., R. M. Blaese, S. Broder, and R. S. Krakauer. 1978 Disorders of suppressor immunoregulatory cells in the pathogenesis of immunodeficiency and autoimmunity. Ann. Intern. Med. 88:226-238.

44. French, M., R. Dawkins, F. T. Christiansen, W. Zhang, M. A. DegliEsposti, and G. Saueracker. 1991. Reply. Immunol. Today. 12:135-136.

45. Todd, J. A. 1990. Genetic control of autoimmunity in type 1 diabetes. Immunol. Today. 11:122-129.

46. Segall, M., and F. H. Bach. 1990. HLA and disease. The perils of simplification. N. Engl. J. Med. 322:1879-1881.

47. Faustman, D., X. Li, H. Y. Lin, Y. Fu, G. Eisenbarth, J. Avruch, and J. Guo. 1991. Linkage of faulty major histocompatibility complex class I to autoimmune diabetes. Science (Wash. DC). 254:1756-1761.

48. Lévi-Strauss, M., M. C. Carroll, M. Steinmetz, and T. Meo. 1988. A previously undetected MHC gene with an unusual periodic structure. Science (Wash. DC). 240:201-204.

49. Mole, J. E., J. K. Anderson, E. A. Davison, and D. E. Woods. 1984 Complete primary structure for the zymogen of human complement factor B. $J$. Biol. Chem. 259:3407-3412.

50. Campbell, R. D., and R. R. Porter. 1983. Molecular cloning and characterization of the gene coding for human complement protein factor B. Proc. Natl. Acad. Sci. USA. 80:4464-4468.

51. Alper, C. A. 1981. Complement and the MHC. In The Role of the Major Histocompatibility Complex in Immunobiology. M. D. Dorf, editor. Garland Publishing Inc., New York, 173-200.

52. Yu, C. Y., K. T. Belt, C. M. Giles, R. D. Campbell, and R. R. Porter. 1986 Structural basis of the polymorphism of human complement components C4A and C4B: gene size, reactivity and antigenicity. EMBO (Eur. Mol. Biol.Organ.) J. 5:2873-2881.

53. Isenman, D. E., and J. R. Young. 1984. The molecular basis for the difference in immune hemolysis activity of the Chido and Rodgers isotypes of human complement C4. J. Immunol. 132:3019-3027.

54. Böttger, E. C., and D. Bitter-Suermann. 1987. Complement and the regulation of humoral immune responses. Immunol. Today. 8:261-264.

55. Bird, P., and P. J. Lachmann. 1988. The regulation of IgG subclass production in man: low serum IgG4 in inherited deficiencies of the classical pathway of C3 activation. Eur. J. Immunol. 18:1217-1222.

56. Ahearn, J. M., and D. T. Fearon. 1989. Structure and function of the complement receptors CR1 (CD35) and CR2 (CD21). Adv. Immunol. 46:183219.

57. Hebell, T., J. M. Ahearn, and D. T. Fearon. 1991. Suppression of the immune response by a soluble complement receptor of B lymphocytes. Science (Wash. DC). 254:102-105.

58. Porter, R. R. 1983. Complement polymorphism, the major histocompatibility complex and associated diseases: a speculation. Mol. Biol. \& Med. 1:161168.

59. Dodds, A. W., S. K. Law, and R. R. Porter. 1985. The origin of the very variable haemolytic activities of the common human complement componen C4 alotypes including C4-A6. EMBO (Eur. Mol. Biol. Organ.) J. 4:2239-2244.

60. Carroll, M. C., D. M. Fathallah, L. Bergamaschini, E. M. Alicot, and D. E. Isenman. 1990. Substitution of a single amino acid (aspartic acid for histidine) converts the functional activity of human complement C4B to C4A. Proc. Natl. Acad. Sci. USA. 87:6868-6872. 